\title{
PESQUISAS COM BEBÊS E CRIANÇAS PEQUENAS: problematizações teórico-metodológicas
}

\author{
Ana Cristina Coll DELGADO ${ }^{1}$ \\ Carolina Machado CASTELLI ${ }^{2}$
}

\begin{abstract}
Resumo
O presente artigo tem como objetivo a proposição de uma abordagem reflexiva acerca de questões teórico-metodológicas no sentido de garantir a visibilidade dos bebês e crianças pequenas nas pesquisas. São discutidos assuntos concernentes aos desafios na entrada em campo, aos acordos, à ética e à necessidade de abordagem dos bastidores das pesquisas. Com foco em preceitos da pesquisa de inspiração etnográfica, são apresentados desafios como a triangulação na interpretação e análise dos dados, a reflexividade e o diálogo com as metodologias visuais. Por último, são expostas questões sobre possibilidades do direito de participação dos bebês e crianças pequenas na geração, análise e discussão dos resultados das investigações e reflexões sobre como as pesquisas combebês e crianças pequenas podem contribuir para a educação infantil.
\end{abstract}

Palavras-chave: Pesquisas. Metodologias. Bebês. Crianças pequenas.

\footnotetext{
${ }^{1}$ Professora colaboradora do Programa de Pós-Graduação da Faculdade de Educação da Universidade Federal de Pelotas - UFPEL, com orientações no Mestrado e Doutorado e Professora colaboradora na Universidade Estadual de Santa Catarina/UDESC. Doutora em Educação pela Universidade Federal Fluminense - UFF (2003), Pós-doutorado na Universidade de Caen, no Centro de Ciências da Educação - França (2009) em sociologia da infância e antropologia da criança, com supervisão de Julie Delalande.

E-mail: anacoll@uol.com.br

2 Doutoranda do Programa de Pós-Graduação em Educação da Faculdade de Educação da Universidade Federal de Pelotas - PPGE/FaE/UFPel e Pedagoga no Núcleo de Desenvolvimento Infantil do Centro de Ciências da Educação da Universidade Federal de Santa Catarina NDI/CED/UFSC. Participa do Grupo de Pesquisa CIC - Crianças, Infâncias e Culturas.

E-mail: m.carolinacastelli@gmail.com
} 


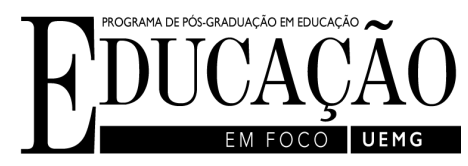

\title{
RESEARCH WITH BABIES AND SMALL CHILDREN: theoretical-methodological problematizations
}

\author{
Ana Cristina Coll DELGADO \\ Carolina Machado CASTELLI
}

\begin{abstract}
The present article aims at proposing a reflexive approach on theoretical and methodological issues in order to guarantee the visibility of infants and young children in research. Issues related to the challenges of entering the field, agreements, ethics and the need to approach the backstage of the research are discussed. Focusing on ethnographic inspiration precepts, challenges such as triangulation in data interpretation and analysis, reflexivity and dialogue with visual methodologies are presented. Finally, questions are raised about the possibilities of the infants' and young children's right of participation in the generation, analysis and discussion of research results and reflections on how research on infants and young children can contribute to early childhood education.
\end{abstract}

Keywords: Research. Methodologies. Infants. Small children. 


\section{Pesquisas com bebês e crianças pequenas: primeiras reflexões}

Os bebês e as crianças pequenas têm sido protagonistas em recentes pesquisas no Brasil, especialmente as realizadas por pesquisadoras/es da educação infantil, em diálogo com os Estudos da Criança. Principalmente pelas disciplinas da Sociologia da Infância e Antropologia da Criança, foi possível pensar nas crianças como participantes com voz, experiências e culturas nas investigações, pois "estas disciplinas apresentam problemáticas de pesquisa para as quais pesquisadoras/es mobilizam análises específicas” (MAYALL, 2009apud DELGADO, 2011, p. 182). Se pensarmos nos bebês, ainda temos muito que avançar nas investigações, possivelmente porque nem todos se comunicam pela linguagem das palavras e caminham.

Apostar nos bebês como dignos de participação em processos investigativosna Sociologia da Infância, na Antropologia da Criança e em áreas como a Psicologia Cultural e a Pedagogia é reconhecê-los enquanto seres humanos capazes, validando suas ações intencionais e culturais, mas que, por muitos, ainda são compreendidas somente como traços biológicos. Conhecer mais os bebês nas suas ações cotidianas e nos seus contextos de vida é uma forma, também, de enxergar as suas necessidades e os seus interesses, refletindo na busca pela garantia dos seus direitos.

Nosso objetivo no artigo é a proposição de uma abordagem reflexiva acerca de questões teórico-metodológicas nas pesquisas com bebês e crianças pequenas. Algumas perguntas parecem oportunas presentemente: por que pesquisar com bebês e crianças pequenas? Qual o impacto das nossas investigações nas suas vidas? Qual o comprometimento político-pedagógico destas pesquisas, no sentido de garantir as conquistas dos direitos proclamados desde o final do século 20 e que compreendem as crianças dessa faixa etária?

São perguntas desafiadoras, pois, no Brasil, as condições de existência dos bebês e das crianças pequenas em situação de pobreza estão ameaçadas, mesmo com as conquistas dos direitos da infância. As condições de existência, quando marcadas pelo aprofundamento das desigualdades sociais, se complexificam somadas ao aumento do desemprego e da fome, às doenças, aos atos de violência sofridos pelos bebês e crianças pequenas e, muitas vezes, invisibilizados e naturalizados.

Liebel (2017) discute a infância latino-americana e analisa que, historicamente, as crianças das camadas populares se encontram expostas à exploração da sua mão de obra, são marginalizadas e discriminadas. Para o autor, há um longo caminho a percorrer até que as crianças possam crescer e viver em igualdade de condições, com dignidade e em pleno exercício dos seus direitos. No caso dos bebês e crianças pequenas, pela sua situação de vulnerabilidade e dependência dos adultos, as condições de pobreza acentuam as desigualdades sociais quando estes não têm acesso à educação, saúde e saneamento básico.

Nossas pesquisas precisam contemplar os modos de viver dos bebês e crianças 
pequenas, que têm pertencimento de classe social, raça, gênero e de geração. Entendemos que meninas e meninos necessitam de maior visibilidade nas pesquisas que se defrontam com grande complexidade, o que tentaremos argumentar ao longo desse artigo. $\mathrm{O}$ quadro teórico que inspira o artigo é dos Estudos da Criança, embora ainda sejam recentes as investigações com bebês neste campo de intersecção entre disciplinas e questionamentos sobre o ponto de vista infantil nas pesquisas, as culturas da infância e a participação das crianças nas investigações e nos seus contextos de vida.

Justificamos a relevância de investigações com bebês e crianças pequenas para que possamos contribuir com outras compreensões sobre os seres humanos de pouca idade, pois os bebês aprendem entre si, como também podem ensinar as gerações mais velhas (ROGOFF, 2005; GOTTLIEB, 2009, 2013; BROUGÉRE; ULMANN, 2012).

Entendemos que é preciso uma articulação entre as contribuições emergentes das pesquisas com crianças e o campo da Pedagogia, especialmente para a Educação Infantil, uma vez que enfatizamos metodologias com bebês e crianças pequenas, o que também requer constante aproximação com as culturas infantis. Portanto, reconhecemos que as pesquisas em escolas infantis acabam sendo campo de pesquisas recentes com bebês também pela necessidade de pensar esse contexto coletivo, somente recentemente incorporado à educação básica em âmbito nacional (BRASIL, 1996), e, também, pela facilidade de acompanhamento de grupos de crianças com certa regularidade.

Ainda assim, destacamos que, embora as pesquisas com bebês em escolas infantis tenham um significativo crescimento, pouco sabemos sobre seus modos de vida e como se dá a sua presença em outros espaços como na cidade, nos parques, nos contextos religiosos, nos hospitais, nos shopping centers, na convivência com os avós, nas casas de acolhimento, entre outros. É indiscutível que a lacuna ainda é significativa, mas os primeiros passos foram dados.

No desenvolvimento do artigo, apresentamos alguns desafios teórico-metodológicos, no sentido de garantir a visibilidade dos bebês e crianças pequenas nas pesquisas. Seguimos com questões concernentes aos desafios na entrada em campo, aos acordos, à ética e à necessidade de abordagem dos bastidores das pesquisas. Pensando em metodologias voltadas para o ponto de vista dos bebês e crianças pequenas, discutimos, na terceira seção, questões concernentes à pesquisa de inspiração etnográfica, o desafio da triangulação na interpretação e análise dos dados, a reflexividade e o diálogo com as metodologias visuais, incluindo desenhos, fotografias e filmagens, estas últimas sobretudo com bebês. Seguimos na quarta seção com o desafio do direito de participação dos bebês e crianças pequenas na geração, análise e discussão dos resultados das nossas investigações. Concluímos o artigo com algumas reflexões sobre como as pesquisas com bebês e crianças pequenas podem contribuir para a educação infantil. 


\section{Desafios teórico-metodológicos pela visibilidade dos bebês e crianças pequenas nas pesquisas}

Um dos desafios da sociologia da infância apontados por Prout (2004) é a interdisciplinaridade como alternativa metodológica para a discussão em torno das incertezas que cercam a infância e os dualismos criados em torno dela, seja como fato natural e psicológico, ou como construção social, histórica e cultural. Nesse sentido, os diálogos com outras disciplinas são necessários frente à complexidade das problemáticas em torno das infâncias e crianças. A Psicologia Crítica, a Psicologia Cultural, as Ciências Médicas e Biológicas são algumas áreas citadas pelo sociólogo, às quais acrescentamos a Pedagogia, pensando nas investigações realizadas no Brasil. É este espírito, segundo Delalande, que tem reunido pesquisadoras/es "dedicados a investigar o ponto de vista das crianças, os seus mundos sociais, as suas experiências e culturas” (DELALANDE, 2009, p. 7-8).

De acordo com Ambert (1996), "sociólogos, antropólogos e psicólogos precisam se aliar no desenvolvimento de pesquisas que respondam às questões de contexto cultural que intervém na vida e no desenvolvimento das crianças” (DELGADO, 2011, p. 198).Ainda argumenta que "a Sociologia da Infância necessita de metodologias diversificadas e rigorosas e não pode cair em um isolamento, ignorando as pesquisas de outras disciplinas, como a Psicologia e a Genética” (AMBERT, 1996, p. 22-24). Montandon (2006) também propõe que os psicólogos, por sua trajetória de experiência com as crianças, se constituam como interlocutores nas pesquisas sociológicas. Todavia, é principalmente pela Sociologia da Infância e pela Antropologia da Criança que as pesquisas têm privilegiado perspectivas "que colocam em evidência a variabilidade da infância no espaço e no tempo" (DANDURAND; HURTUBISE; LE BOURDAIS, 1996apud DELGADO, 2011, p. 182).

Por conseguinte, ressaltamos que os bebês, assim como as demais crianças, são pessoas que vivem e participam da construção social e cultural das infâncias em diferentes contextos temporais e espaciais e são produtores de culturas. Especialmente os bebês possuem modos específicos de existência devido às suas maneiras exóticas de comunicação (GOTTLIEB, 2009). Muito do conhecimento que foi produzido sobre os bebês e crianças pequenas carrega marcas adultocêntricas nas pesquisas "sobre" este grupo social da infância sem considerar sua capacidade de participação “com” pesquisadoras/es. Este adultocentrismo ainda é presente quando os adultos responsáveis pelos bebês e crianças pequenas desconfiam que eles possam ser informantes potenciais em nossas investigações.

Inclusive as crianças maiores, por terem vivido mais experiências em escolas de educação infantil e em outras instâncias da sociedade, podem apresentar posturas adultocêntricas, quando manifestam crenças sobre a incapacidade, inferioridade e imaturidade dos bebês, numa reprodução de como parte da sociedade se comporta com os que não falam a linguagem das palavras ou não caminham. 
É indiscutível que a Psicologia do Desenvolvimento acumulou muitas pesquisas sobre bebês (desde os de colo até aqueles com quase dois anos de idade, uma vez que a definição sobre quem são os bebês é cultural), mas cabe enfatizar que, em sua maioria, foram estudos focados especialmente em "bebês e crianças pequenas europeus, americanos, brancos, de classe média, cujos resultados têm sido universalizados e naturalizados" (GOTTLIEB, 2013 apudDELGADO; WÜRDIG; CAVA, 2017, p. 147). A visibilidade da qual falamos está relacionada com a produção de investigações voltadas ao conhecimento dos seus mundos sociais e culturais, que destaquem seus diferentes pontos de vista, com valorização das suas heterogeneidades e complexidades, considerando que também são atores sociais, ainda que dependentes dos adultos e vulneráveis.

Observando bebês e crianças bem pequenas em tribos africanas, no convívio com outros grupos geracionais, manuseando e utilizando materiais pontiagudos ou que envolvessem fogo, Rogoff (2005) argumenta não haver uma correspondência universal entre idade e aprendizagem, por esta estar relacionada às possibilidades de observação e participação em atividades socioculturais. Considerar os bebês e crianças pequenas como atores sociais nos seus mundos de vida configura-se numa proposição política, pois eles têm muito a contribuir com as mudanças sociais. Implica reconhecer que também participam dos momentos de trocas de fraldas, das interações com outras crianças e com adultos e "de processos de ajustamentos e, por isso, também transformam e perpetuam a sociedade” (MOLLO-BOUVIER, 1997; SARMENTO, 2007apud DELGADO, 2011, p. 185). Conforme Rayou (1999, p.2), trata-se de "interrogar os paradigmas estruturaisfuncionalistas” de socialização, e as pesquisas que apontam as ações e produções das crianças indicam que a socialização não é um processo unilateral (DELGADO, 2011).

Porém, ainda temos poucas pesquisas sobre a agência dos bebês nos processos de socialização. Gottlieb assevera que a "aparente ausência de racionalidade por parte dos bebês os coloca em risco de terem uma adaptação problemática à categoria de 'humano"” (GOTTLIEB, 2013, p. 110), o que reflete no pouco investimento nas pesquisas realizadas com eles nas áreas das Ciências Humanas. Para a autora, a visão que identificou como predominante era a de bebês como biopacotes (GOTTLIEB, 2013). Na mesma direção desse pensamento, destacamos que, nos anos de 1970, “a célebre frase de Françoise Dolto de que o bebê é uma pessoa causou impacto na sociedade ocidental, uma vez que o bebê era considerado simplesmente como um tubo digestivo" (NEYRAND, 2000, p. 16).

Reconhecemos que junto a essa visão coexistiam outras concepções, sobretudo entre mulheres não ocidentais, que consideravam aspectos para além dos biológicos nos modos de entender e viver com os bebês. Entretanto, para a ciência, a visão ocidental branca e masculina predominante também refletia nos bebês, seja na ausência de interesse em pesquisá-los, seja nas metodologias, individuais, comportamentais e laboratoriais.

Pensar nos bebês e crianças pequenas como atores sociais é reconhecer que eles têm um papel de protagonismo coletivo nos processos de socialização e compreender as suas 
ações não como exclusivamente naturais ou biológicas amplia as possibilidades investigativas para os campos da cultura, das relações sociais e dos percursos educativos, requerendo a reinvenção de metodologias de pesquisa.

Retomando os argumentos de Prout (2004), é preciso superação dos dualismos, pois os bebês são potentes e dependentes, diferentes e singulares nas suas manifestações em contato com o mundo. Colocamo-nos, portanto, numa postura de reflexão sobre como garantir, por um lado, a validade da produção de conhecimentos com crianças que utilizam prioritariamente outras formas de expressão que não a falada, e assegurar, por outro, o respeito a elas nas investigações enquanto pessoas com especificidades pela geração sincrônica e diacrônica em que se encontram (DELGADO; MARTINS FILHO, 2013).

Pesquisar é um exercício plural, de acordo com os referenciais e objetos ou participantes da pesquisa. É, igualmente, uma prática cultural, regulada pelas discussões morais e éticas, e que incorpora as transformações tecnológicas. Pesquisar com crianças ou com bebês implica, como postula Corsaro (2011), manter o rigor científico, isto é, trabalhar com os métodos de pesquisa já validados, mas os adaptando e refinando às particularidades das gerações infantis, mantendo uma abertura para o novo, que emerge do encontro com as crianças.

Dentro da perspectiva teórica em que nos situamos, têm se destacado as propostas metodológicas baseadas nos preceitos da etnografia. Embora muito ainda precise ser discutido sobre a apropriação da etnografia por pesquisadores externos à Antropologia, o seu uso, ou melhor, o desenvolvimento de propostas metodológicas inspiradas ou apoiadas em princípios etnográficos tem se mostrado potente nas investigações com bebês e demais crianças.

Essa potência é encontrada tanto com relação à compreensão das crianças e dos bebês como grupos possíveis de serem investigados enquanto possuidores de modos de vida próprios e culturas particulares, quanto pelas orientações metodológicas e instrumentos propostos, que permitem uma compreensão mais próxima às lógicas infantis, as quais, muitas vezes, não passam pela ordem da palavra. É na direção de discutir e ressaltar essa potência que seguiremos a reflexão.

\section{Aproximações aos mundos de vida dos bebês e crianças bem pequenas: acordos e assentimento}

Para entrar no mundo dos bebês e das crianças pequenas, para além do consentimento de algum adulto responsável por cada um, precisamos do assentimento das meninas e meninos. Nas palavras da pesquisadora Manuela Ferreira, se faz necessário considerar os "processos em curso para obter a permissão das crianças a fim da sua observabilidade ser por elas aceite” (2010, p. 177), o que implica, conforme argumenta, o 
estabelecimento de relações de confiança entre as crianças e as/os investigadoras/es, desenvolvendo-se de maneira ambígua e renegociada.

Sarmento (2004, p.12) discorre sobre as dimensões relacionais, isto é, as interações entre as crianças e delas com os adultos, pois elas "produzem formas especificamente infantis de inteligibilidade, representação e simbolização do mundo”, o que evidentemente repercute em todo o processo de investigação. Saber ler e compreender estas formas de interpretar e representar o mundo pelos bebês e crianças pequenas torna-se um desafio para pesquisadoras/es adultas/os.

Em recentes pesquisas brasileiras na área da educação dedicadas a essa faixa etária (SCHMITT, 2008; COUTINHO, 2010; GOBBATO, 2011; PEREIRA, 2011, 2015; FOCHI, 2013; CASTELLI, 2015; DELGADO; WÜRDIG; CAVA, 2017; entre outros), encontramos referências de que bebês e crianças pequenas falam de diversas maneiras nas suas diferentes formas de expressão, sendo capazes de produzir saberes e conhecimentos sobre o mundo, pela via das culturas infantis. Os desafios na entrada em campo e nos acordos têm relação com seus jeitos de comunicação e expressão, nem sempre facilmente interpretados pelas/os pesquisadoras/es, pois a linguagem da não palavra exige observação e escuta para expressões, gestos, movimentos, risos, balbucios, que exigem um tratamento cuidadoso nas pesquisas (DELGADO; MARTINS FILHO, 2013).

Como enfatiza a cineasta francesa Claire Simon, "as crianças estão prontas a mudar de ponto de vista a todo o momento, pois é a pulsão que as leva, elas são, a todo tempo, invadidas pela ambivalência, o que não entra no esquema de uma sociedade estruturada" (2006, p. 93). No que diz respeito aos bebês e crianças pequenas, estas questões se complexificam, pois não participam das pesquisas como o fazem os adultos.

Sobre a entrada em campo e os acordos, é relevante explicar às crianças e aos seus familiares os objetivos de nossas investigações, mas certamente há jeitos e formas diferentes de contar sobre nossas intenções para os bebês e crianças bem pequenas. E como adverte Ferreira, os bebês e crianças pequenas nos observam e nos pesquisam, assim como identificam "nossos pressupostos adultocêntricos e constroem interpretações reflexivas acerca do nosso desempenho na investigação” (2002, p. 150-151).

Somos chamadas/os para resolver conflitos e para descumprir ordens dos adultos, principalmente quando estes estão distantes. Mas também podemos ser ignoradas/os por alguns bebês e crianças pequenas, ou muito solicitados por outros. Destacamos a recusa de alguns em participar das investigações, o que pode ocorrer em diferentes fases, com alternâncias de aceitação e recusa. Um exemplo: algumas crianças pequenas, em pesquisa já concluída (DELGADO, 2010), participaram com entusiasmo na produção de fotografias, o que não aconteceu com o mesmo vigor quando fomos conversar sobre as suas composições fotográficas. Principalmente nas suas casas e, eventualmente, na escola infantil, elas pareciam intimidados pela situação de face a face. Danic(2006, p. 168) explica que algumas vezes “[...] as crianças se mostram aborrecidas frente ao pesquisador: elas 
sabem exprimir seu aborrecimento e encurtar a situação cessando toda cooperação (sinais de impaciência, gritos, respostas fantasiosas sem levar em conta a questão [...]" (DELGADO, 2010).

Neste sentido, a ética é um aspecto fundamental, pois é inegável que existe uma força adulta baseada no tamanho físico, nas relações de poder e nas decisões arbitrárias. O debate sobre as questões éticas nas pesquisas com bebês e crianças pequenas exige reflexividade de pesquisadoras/es adultas/os, no sentido de garantir à criança o direito de consentir ou não em participar da pesquisa (DELGADO; MÜLLER, 2005a), para além da autorização prévia concedida por seu(s) pai(s) ou representante(s) legal(is). Com bebês e crianças pequenas, nem sempre a recusa será tão explícita verbalmente. A mesma pode se dar através de choros, evitação, ou no meio de uma brincadeira.

Soares (2003) define a ética nas pesquisas com crianças como um equilíbrio entre respeito, autonomia e proteção e uma concepção das crianças como um grupo social com direitos. Ela aponta alguns passos de um roteiro ético em pesquisas com crianças: considerar se o projeto pode traduzir-se em conhecimento válido acerca dos significados das crianças; considerar os custos de tempo, medo, coerção e ansiedade para as crianças; considerar e respeitar a privacidade e confidencialidade das crianças; considerar as informações que os pais ou responsáveis legais das crianças têm do processo de investigação; considerar a forma como as crianças serão selecionadas para integrar a equipe de investigação, obter o assentimento das crianças e garantir que elas podem recusar participar do processo ou desistir a qualquer momento (SOARES, 2003).

Ferreira escreve que "o processo de aceitação e o estabelecimento de relações de confiança entre investigador e crianças é desigual, plural e pode permanecer ambíguo" (2002, p. 150). As crianças, desde bebês, fazem sentido sobre as coisas que vivem. Não bastassem outras possíveis diferenças, a questão geracional entre pesquisador(a) e bebês ou crianças é questionada por elas, uma vez que, por já terem experiências com outros adultos, sabem que estes esperam delas determinadas respostas ou comportamentos. Corsaro (2011) foi um dos primeiros pesquisadores a dar ênfase a essa questão da relação com as crianças na pesquisa. Mesmo tendo seus métodos atualmente questionados, como o faz Marchi (2018), o fato de ter se preocupado sobre os modos como o(a) pesquisador(a) deveria entrar em campo e que postura adotar nesse contexto demonstrou a necessidade de essas questões também serem refletidas, levando em conta o olhar da criança nesse processo.

Ainda com relação à participação dos bebês e das crianças pequenas nas investigações, também é preciso considerar que ocorrem dificuldades em acessar e manter o estabelecimento de contato com alguns/as e suas famílias. Mesmo quando as pesquisas são realizadas em escolas infantis, os grupos nem sempre são coesos e estáveis, o que pode ser ainda mais evidente em outras instituições ou contextos extraescolares. Alguns elementos que têm sido percebidos nesse sentido são condições climáticas desfavoráveis, 
doenças, dificuldades de locomoção de familiares, mobilidade das camadas populares, dificuldade de acesso a famílias de classes média e alta, entre outras. As desigualdades sociais e dilemas contemporâneos são indicadores das possibilidades ou limitações de participação dos bebês e seus familiares nas combinações estabelecidas.

Por último, do ponto de vista de Danic (2006, p. 162-163apud DELGADO, 2010), “dificilmente os pesquisadores expõem os bastidores de uma pesquisa, porque isto não é indispensável na apresentação dos resultados e seus erros seriam expostos”. Acreditamos que omitir "os bastidores" da pesquisa é reflexo do olhar seletivo do pesquisador. O ato de pesquisar implica seleção e categorização. E cada pesquisador faz isso a partir do conjunto de lentes teóricas e experiências investigativas. Não considerar os dados intrínsecos à realização da pesquisa é adotar um recorte focado nos objetivos propostos para o estudo, mas que não se abre ao novo, ao imprevisto, às tentativas frustradas, ao que não deu certo. E justamente esses aspectos, comumente descartados, como detritos (BENJAMIN, 2009), os restos (PIORSKI, 2013) e os desperdícios (BARROS, 2008), que tanto interessam às crianças, podem indicar apontamentos importantes no que se refere ao conhecimento e à consideração dos seus modos de vida, bem como com relação às metodologias de pesquisa com essa faixa etária.

\section{Etnografia com bebês e crianças pequenas: a triangulação na geração dos dados}

Para Sarmento (2003apud DELGADO; MÜLLER, 2005b, p. 168-169),“a etnografia visa a apreender a vida, tal como ela é cotidianamente conduzida, simbolizada e interpretada pelos atores sociais. A vida é, portanto, plural nas suas manifestações, imprevisível e ambígua nos seus significados”. Isto nos desafia a renunciar a definição de critérios universais de verdade, assim como a pensar nas crianças como capazes de interpretar e dar novos sentidos às relações que experimentam com o mundo, com outras crianças e adultos (SARMENTO, 2003).

Outras três características importantes são apontadas por autores como Geertz (1989), Corestein (1993) e Dauster (1989) - que argumentam que as raízes da pesquisa etnográfica podem ser encontradas na Antropologia.Uma delas refere-se ao uso das técnicas comumente associadas à etnografia: observação participante, entrevista semiestruturada e análise documental. Porém, a pesquisa não se caracteriza somente pelas técnicas ou processos que possamos utilizar, mas, fundamentalmente, pela interpretação minuciosa e arriscada que faremos a partir dos dados coletados (ERICKSON, 1986; GRAUE; WALSH, 2003).

A segunda característica é a possibilidade de redefinir a metodologia durante o desenvolvimento do trabalho. Enfatiza-se, pois, o processo (aquilo que ocorre no transcorrer da pesquisa) e não apenas o produto ou os resultados finais. A terceira diz 
respeito à necessidade de um contato direto e prolongado do pesquisador com o ambiente e a situação investigada, pois, devido à flexibilidade do plano de trabalho, "os focos da investigação vão sendo constantemente revistos, as técnicas de coleta reavaliadas, os instrumentos reformulados e os fundamentos teóricos repensados”(ANDRÉ, 1995, p. 30).

Nesse sentido, compreendemos que a pesquisa de inspiração etnográfica é uma proposta metodológica que vem ganhado espaço nas investigações com bebês e crianças pequenas, "pois aprofunda a dimensão cultural e permite construir novos objetos de estudo sobre as crianças e suas ações” (DELALANDE, 2009, p. 35). Graue e Walsh defendem que "os investigadores pensem nas crianças em contextos específicos, com experiências específicas e em situações da vida real” como elas negociam e interagem em grupos, "o que se passa ‘entre’ elas, e não ‘dentro’ delas” (2003, p. 22). Existe uma abertura para a criação de metodologias com as crianças consideradas participantes nas pesquisas e que possibilitam maior expressão delas entendendo que suas linguagens não abrangem somente a oralidade, conforme temos argumentado no artigo.

Nas pesquisas com bebês e crianças pequenas, é a escuta atenta de como produzem significados, de como vivem suas experiências e produzem culturas que possibilita o esforço de interpretação minucioso e arriscado dos dados gerados com as crianças, o que nos remete a Geertz (1989). Pelo fato dos bebês se comunicarem para além da linguagem da palavra, os instrumentos metodológicos utilizados têm sido aqueles que possibilitam o registro de outras formas de expressão, como a observação participante com notas em diários de campo, filmagens e fotografias, diários das crianças com registros escritos, desenhos das crianças, inclusive nos nossos diários de campo, sempre de acordo com as possibilidades dos grupos de idade e dos seus contextos.

Quando pesquisamos com crianças que já dominam a linguagem verbal, é possível lançar mão de métodos mais sistemáticos, como a produção de desenhos, o registro fotográfico por parte das crianças, que pode vir a ser comentado posteriormente por elas, a realização de entrevistas em pequenos grupos de crianças, ou de entrevistas conduzidas por elas próprias. Ao propormos entrevistas conduzidas pelas crianças, é interessante destacar que elas fazem entrevistas paralelamente a jogos de faz de conta, nos quais pesquisadores adultos são convocados a participar.

Comumente, nos deparamos com o necessário desafio da triangulação na interpretação e análise dos dados. Denzin (1978) entende que a triangulação combina diferentes formas de análise,o que pode suceder por intermédio da geração dos dados (diversas fontes), dos investigadores (grupo com mais de um pesquisador), da teoria (múltiplas perspectivas ou teorias) e da metodologia (variados métodos).

Este movimento de interpretação permite analisar os dados a partir de nosso ponto de vista (adultos pesquisadores) e do ponto de vista das crianças, sendo que o desenho dos instrumentos e negociações acontece durante todo o processo de pesquisa. Tal processo exige reflexividade constante, uma vez que estamos muito distantes dos bebês e crianças 
pequenas em termos de tamanho físico, de comunicação corporal e verbal, e dos modos de interpretar e representar o mundo.

De acordo com Brougère (2003), adultos e crianças não têm a mesma relação com a imagem, tampouco as mesmas referências culturais para interpretá-las. Por conta disso, a inclusão do ponto de vista dos bebês na pesquisa significa valorizar seus conhecimentos, culturas e experiências. Por isso, consideramos importante o diálogo com as metodologias visuais, incluindo desenhos, fotografias e filmagens, sobretudo com bebês. No que diz respeito ao desenvolvimento da Antropologia Visual, Bonnet e Pourchez (2007) explicam que "a tomada de consciência do papel da imagem na construção do olhar sobre o outro é presente desde os primórdios da disciplina e Margaret Mead e Gregory Bateson introduziram o filme etnográfico nos ensinamentos de Antropologia”, no que diz respeito as possibilidades de análise e comparações propiciadas pelas imagens (DELGADO, 2011, p. 200).

Ao refletir sobre as imagens, Andrade indica que elas são como “[...] observações estéticas e documentais da realidade e a fotografia e a etnografia podem contribuir entre si; como os processos de observação da ciência e da arte podem completar-se e não atritar-se" (2002, p. 18). Como observam Christensen e James (2005), os comentários sobre fotografias, quando combinados com outros métodos - como a observação participante podem permitir a exploração de determinados assuntos com maior profundidade e fornecer uma espécie de triangulação metodológica (DELGADO, 2010; 2011).

Um outro aspecto relevante diz respeito aos modos como nos relacionamos corporalmente com as crianças. Corsaro $(2005,2009)$ foi um dos primeiros pesquisadores a perceber a relevância das diferenças de tamanho físico entre adultos e crianças nas investigações. Ele percebeu nas suas pesquisas "que adultos raramente entravam nas casas de boneca, nas caixas de areia, ou no trepa-trepa e decidiu adotar uma estratégia de entrada reativa em campo" (CORSARO, 2005, p. 448). Mesmo antes disso, no início do século XX, JanuszKorczak já alertava para a supremacia da sociedade adulta e desconfiava de um mundo governado pelos adultos:

Todos nós crescemos convencidos de que o grande vale mais do que o pequeno(...)Paraconquistar respeito e admiração é preciso ser grande, ocupar muito espaço. O que é pequeno é banal e desinteressante. Gente pequena, necessidades pequenas, pequenas alegrias e tristezas (DALLARI; KORCZAK, 1986, p. 69).

Quando fazemos anotações em diários de campo, fotografamos ou filmamos acompanhando e escolhendo cenas que parecem mais adequadas com nossas questões de pesquisa, há que se ter cuidado com nossa postura corporal com bebês e crianças pequenas. Mas não apenas nestas situações. Estar e interagir com estes grupos de idade requer uma relação de igualdade que acontece quando nos colocamos na altura das crianças e não acima delas.Filmar de pé se torna um desafio para que não sejam perdidos nuances e detalhes que exigem que estejamos na mesma altura deles. 
Corsaro (2011) e Carpenter (2010) apontam que as crianças sentem necessidade de se ocultar dos adultos, separando aquilo que pertence ao seu mundo do que pertence aos adultos. Os espaços ocupados pelas crianças, muitas vezes esconderijos ou cantos, são distintos daqueles ocupados pelos adultos em razão da sua corporeidade, do seu tamanho e dos modos como se movimentam e essas formas de se relacionar com o mundo repercutem nas pesquisas de que participam (DELGADO; WÜRDIG; CAVA, 2017).

\section{Participação dos bebês e crianças pequenas na produção e análises dos dados}

Nas formas como registramos os dados gerados nas investigações, temos como desafio pensar em como apresentaremos estes dados às pessoas exteriores às culturas dos bebês e crianças pequenas, sejam elas pertencentes à comunidade acadêmica, ou de outros grupos. Um outro desafio diz respeito à participação dos bebês e crianças na geração, análise e discussão dos resultados das nossas investigações. Isto é possível? Como seria sistematizado?

Considerando diferenças geracionais, podemos negociar com as crianças todos os aspectos e etapas das investigações: a entrada no campo e nossos objetivos, quais crianças querem realmente participar da pesquisa e contribuir com a geração de dados, os acordos e negociações que também envolvem a divulgação e o destino do material de campo. É importante que adotemos uma postura de reflexividade constante, no sentido de nos perguntar se "fazemos uma boa abordagem dos dados coletados com as crianças, se os compreendemos e os interpretamos bem” (MONTANDON, 2006, p. 48).

Essa também é uma preocupação ética, que perpassa todas as instâncias da pesquisa - e não somente o uso de imagem ou a exposição (ou não) dos nomes dos participantes. A ética começa na consideração dos bebês e crianças como capazes de participação e merecedoras do direito de escolha à essa participação. A reflexividade também se manifesta entre bebês e crianças pequenas, pois eles se posicionam em todas as instâncias da investigação.

Neste sentido nos perguntamos: o que seria adotar o ponto de vista dos bebês e das crianças pequenas? Lembrando que não conseguimos ser inteiramente fidedignos ao que elas e eles pensam e dizem sobre o mundo, pois temos limites como intérpretes e tradutores desses pontos de vista na comunidade acadêmica. Seria prepotência acreditar que é possível captar inteiramente a riqueza e a versatilidade das suas respostas e criações, da mesma forma que não conseguimos captar todas as sutilezas e delicadezas de uma obra de arte. Françoise Dolto (1985) defende que considerar o mundo segundo o ponto de vista dos bebês pressupõe escutar suas linguagens e aprender a conversar com eles, sem, contudo, impor a nossa linguagem.

A escuta dos bebês revela um espírito revolucionário. Vem da ideia de que ele é 
uma pessoa, decorrente dos trabalhos conduzidos por Françoise Dolto (1985), os quais elucidam a emergência de uma nova percepção acerca deles e de seus afetos. Como destaca a autora: "o bebê entende tudo o que lhes dizemos; ele compreende. Como? Eu creio que ele compreende toda linguagem, mesmo se nós falamos chinês” (DOLTO, 1985, p.554). Bebês e crianças pequenas observam e analisam pesquisadoras/es, procuram se empoderar dos nossos diários de campo, de filmadoras e câmeras fotográficas desmistificando a relação de supremacia dos adultos investigadores sobre as crianças como informantes passivos.

Soares (2006) define três patamares presentes na participação das crianças na investigação: o patamar da mobilização, processo iniciado pelos adultos, em que as crianças são convidadas a participar das nossas pesquisas; o patamar da parceria, processo desenvolvido em parceria entre os adultos com as crianças; e o patamar do protagonismo, processo que depende da ação das crianças e no qual adultos são consultores disponíveis e presentes.

O patamar da mobilização é um processo iniciado pelos adultos e as crianças são convidadas a participar, como também são consideradas ao recusarem participar de alguma etapa da pesquisa. Este patamar parece predominar nas pesquisas que desenvolvemos com bebês e crianças pequenas. Cabe ressaltar que bebês e crianças pequenas participam das nossas pesquisas e isso ocorre mesmo quando estão somente observando; isto é, uma antecipação de participação, pois participar é aprender e aprender é participar (BROUGÈRE; ULMANN, 2012).

As suas formas de participação não acontecem hegemonicamente: estabelecem estratégias e criação de vínculos entre elas e adultos, que consistem em formas de negociação, aceitação, estabelecimento de papéis por meio de interações nas quais são vivenciadas diferentes formas de participação e relações de poder.

No caso dos bebês, ainda predominam concepções adultocêntricas marcadas pela proteção e ações de vigiar seus movimentos e deslocamentos, incluindo as pesquisadoras em algumas situações. Nas relações intergeracionais (entre adultos e crianças) são mais presentes características do paradigma de proteção e controle (TOMÁS; SOARES, 2004). Não podemos esquecer que os bebês e crianças pequenas são mais vulneráveis e dependentes da proteção e cuidados dos adultos, inclusive estas características vão produzir marcas nas relações que mantemos com estes grupos durante os processos de pesquisa. Todavia, nesses processos devemos refletir sobre atitudes de proteção e controle, ou de representações de que bebês e crianças pequenas são pouco participativos nas pesquisas. Importante é a atitude constante de reflexividade sobre nossas atitudes nas investigações.

A construção da participação não é um ato como dar ou tirar poder, por parte dos adultos. Nesse sentido, a participação dos bebês e das crianças pequenas nas pesquisas deve reconhecer esta rede de relações, em constante tensão, ao invés de um privilégio que adultos detêm nos processos de investigação. Logo, a participação infantil nesses processos 
é um direito que deve ser assegurado nas pesquisas, o que também pressupõe capacidade de escuta e de observação por parte dos adultos, uma vez que bebês se comunicam pincipalmente pela linguagem corporal.

Para Grahan e Fitzgerald (2010), ainda não sabemos teorizar, interpretar e implementar a participação das crianças na vida social e política. Há uma interação complexa entre possibilidades e limites que deve ser documentada a partir daquilo que as crianças têm a dizer (e merecem dizer) sobre a sua participação nas nossas investigações (DELGADO; CASTELLI; BARBOSA, 2015).

\section{Como as pesquisas com bebês e crianças pequenas podem contribuir para a educação infantil?}

Identificamos a necessidade de ampliar investigações etnográficas e análises que compreendam as experiências e conhecimentos dos bebês e crianças pequenas, em uma complexa tarefa de considerar contextos micros e macros, locais e globais, sem cair na simples polarização. E reiteramos que isto exige diálogos com outros campos do conhecimento, ainda que a Sociologia da Infância e a Antropologia da Criança tenham oportunizado uma abertura para a criação de metodologias investigativas construídas com as crianças consideradas participantes nas pesquisas.

São campos atuantes como movimentos de resistência e que tem muito a contribuir com os direitos das crianças, em variados âmbitos e não somente na educação da infância. Por isto, a necessidade de investigações em outros contextos de vida dos bebês e das crianças pequenas. Defendemos que, ao tomarmos conhecimento de mais aspectos das suas vidas, em diferentes culturas e campos do conhecimento, nos tornamos mais capazes do exercício de estranhamento que pode levar a outras possibilidades de acolher as crianças nas instituições de educação infantil (CASTELLI; DELGADO, 2017). Possibilidades, estas, que sejam de mais escuta e abertura ao que as crianças propõem - e que muitas vezes não é colocado por meio da palavra.

Reconhecemos que ainda falta caminharmos na aproximação do retorno das investigações às escolas. Embora a educação infantil seja campo de muitas das recentes publicações, questionamos o que podemos fazer para que os resultados dessas pesquisas chegam às instituições, no sentido de serem discutidas entre as/os professoras/es e fomentarem a sua prática. Acreditamos em uma via de mão dupla: uma maior valorização dos bebês e crianças pequenas, que tem emergido por meio de mais pesquisas, pode levar a um maior reconhecimento do trabalho das/os professoras/es; e considerar os saberesfazeres docentes, ampliando os processos de formação inicial e continuada, contribui para uma maior visibilidade dos bebês e crianças (CASTELLI, 2015).

Romper com uma cultura adultocêntrica nas escolas infantis é um grande desafio, por isso, as investigações com bebês e crianças pequenas podem fomentar processos de 
reflexão sustentados na participação infantil nos processos educativos. Um exemplo são as pesquisas com foco nas culturas da infância e que geram implicações pedagógicas, como: pensar o trabalho pedagógico com as crianças; pensar as crianças como atores sociais; pensar a educação a partir da prática e não da prescrição. O trabalho pedagógico deve ser pensado em torno da construção de um cotidiano que tenha significado para a criança, com sentido de uma existência partilhada e coletiva. Este trabalho pode oportunizar o direito de participação das crianças, normalmente pouco considerado no campo pedagógico, buscando a força que cada criança tem no desempenho coletivo.

Por último, alertamos para o fato de que a infância, enquanto grupo social e geracional da qual fazem parte bebês e crianças pequenas, não pesquisa academicamente sobre si mesma, mas pode contribuir com as mudanças sociais e, em especial, educacionais. Reconhecemos a importância do comprometimento de investigadoras/es sensíveis à interlocução com bebês e crianças pequenas em buscar traduzir as suas diferentes formas de ação e participação que, embora ainda pouco reconhecidas, têm nos demonstrado que temos muito ainda o que aprender com eles. Esperamos que surjam mais pesquisas com bebês e crianças pequenas no Brasil, embora cientes dos desafios que enfrentamos na atualidade para a realização de investigações nas ciências humanas.

\section{Referências}

ANDRADE, R. Fotografia e antropologia:olhares fora-dentro. São Paulo: Estação Liberdade/EDUC, 2002.

ANDRÉ, M. E. D. A de. Etnografia da Prática Escolar. São Paulo: Papirus, 1995.

AMBERT, A.-M. Perspectives internationalessurlasociologiedesenfances: organization de la Science et paradigmes de recherche. In: DANDURAND, R.; HURTUBISE, R.; LE BOURDAIS, C. Enfances Perspectives Sociales et Pluriculturelles. Sante-Foy: LesPresses de L’ UniversitéLaval, InstitutQuébécois de Recherchesurlaculture, 1996. p. 11-27.

BARROS, M. de. Memórias inventadas: As Infâncias de Manoel de Barros. São Paulo: Editora Planeta do Brasil, 2008.

BENJAMIN, W. Reflexões sobre a criança, o brinquedo e a educação. 2. ed. São Paulo: Duas Cidades: Editora 34, 2009.

BRASIL. Lei $n^{\circ}$ 9.394, de 20 de dezembro de 1996. Lei de Diretrizes e Bases da Educação. Diário Oficial da União, Brasília, 23 dez. 1996.

BONNET, D.; POURCHEZ, L. Du soinauritedansl'enfance. Paris: Èrès, 2007.

BROUGÈRE, G. Jouets et compagnie. France: Éditions STOCK, 2003.

BROUGÈRE,G.;ULMANN,A.-L.Aprenderpelavidacotidiana.

Campinas:Autores Associados,2012.

CARPENTER, C. Lesuniversaux de lacultureenfantine. In: ARLEO, A.; DELALANDE, J. Culturesenfantines:Universalité et diversité. Rennes: PressesUniversitaires de Rennes, 2010. p. 45-57.

CASTELLI, C. M. “Agora quando eu olho pra ele, ele sorri pra mim, porque a gente começou a ser amigo”: o que fazem juntos bebês e crianças mais velhas em uma escola de Educação Infantil. 2015. 293 f. Dissertação (Mestrado em Educação) - Faculdade de 
Educação, Universidade Federal de Pelotas, Pelotas, 2015.

; DELGADO, A. C. C. Entre amas de leite, especialistas, mães e creches: concepções sobre bebês no Brasil. Educação, Porto Alegre, v. 40, n. 3, p. 375-385, set./dez. 2017.

CHRISTENSEN, P.; JAMES, A. Investigação com crianças: Perspectivas e práticas. Porto: Ediliber Editora de Publicações, 2005.

CORESTEIN, M. La Investigacion Etnografica. Intríngulis, México, D. F., n. o 7, 1993.

CORSARO, W. Entrada no campo, aceitação, e natureza da participação nos estudos etnográficos com crianças pequenas. In: DELGADO, A. C. C.; MÜLLER, F. Dossiê: Sociologia da infância: pesquisa com crianças. Educação \& Sociedade, Campinas, v. 26, n.91, p. 443-464, 2005.

. Métodos etnográficos no estudo da cultura de pares e das transições iniciais na vida das crianças. In: MÜLLER, F.; CARVALHO, A. M. A. Teoria e Prática na Pesquisa com Crianças: Diálogos com William Corsaro. São Paulo: Cortez, 2009, p. 83-103.

Sociologia da Infância. Porto Alegre: Artmed, 2011.

COUTINHO, Â. S. A ação social dos bebês: um estudo etnográfico no contexto da creche. 2010. 311 f. Tese (Doutoramento em Estudos da Criança Especialidade em Sociologia da Infância) - Instituto de Educação, Universidade do Minho, Braga, 2010.

DANIC, I.; DELALANDE, J.; RAYOU, P. Enquêterauprès d'enfants et de jeunes. Objets, méthodes et terrains de rechercheensciencessociales. Rennes: PressesUniversitaires de Rennes, 2006. p. 162-192.

DALLARI, D. de A.; KORCZAK, J. O direito da criança ao respeito. Tradução de Yan Michalski. São Paulo: Summus, 1986.

DANDURAND, R.; HURTUBISE, R.; LE BOURDAIS, C. Enfances Perspectives Sociales et Pluriculturelles. Sante-Foy: LesPresses de L' UniversitéLaval, InstitutQuébécois de Recherchesurlaculture, 1986.

DAUSTER, T. Relativização e Educação - Usos da Antropologia na Educação. In: Encontro Anual da ANPOCS, 13, 1989, Caxambu. Anais... Caxambu: ANPOCS, 1989. p. 1-15. Disponível em: <http://anpocs.org/index.php/encontros/papers/13-encontro-anual-daanpocs/gt-14/gt25-6/6822-taniadauster-relativizacao/file>. Acesso em: 03 dez. 2018.

DELALANDE, J. (org.). Des enfants entre eux:Des jeux, desrègles, dessecrets. Paris: ÉditionsAutrement. CollectionMutations, 2009.

DELGADO, A. C. C. Composições fotográficas das crianças sobre o papel dos adultos e participação infantil nas festas dedicadas a infância. Revista Educação em Questão, Natal, v. 38, n. 24, p. 138-163, mai./ago. 2010.

Estudos socioantropológicos da infância no Brasil:caminhos, problematizações e diálogos. In: MARTINS FILHO, A.; PRADO, P. D. Das pesquisas com crianças à complexidade da infância. Campinas: Autores Associados, 2011. p. 181-203.

; CASTELLI, C. M.; BARBOSA, F. A. P. As programações do mês da criança: ambiguidade e poder na participação dos bebês e crianças pequenas. Investigar em Educação, Porto, v.4, p. 83-96, 2015.

; MARTINS FILHO, A. J. (orgs.). Dossiê "Bebês e crianças bem pequenas em contextos coletivos de educação”. Pro-Posições, Campinas, v.24, n. 3 (72), p. 21-113, set./dez. 2013.

; MÜLLER, F. Dossiê: Sociologia da infância: pesquisa com crianças. Educação \& Sociedade, Campinas, v. 26, n.91, p. 351-360, 2005 a.

Em busca de metodologias investigativas com as crianças e suas culturas. Cadernos de Pesquisa, São Paulo, v. 35, n. 125, p. 161-179, maio/ago. 2005b. 
;WÜRDIG, R. C.; CAVA, P. P. Interatividade nas culturas da infância: aproximações, amizade e conflitos entre bebês. Revista Educação em Questão, Natal, v. 55, p. 144-168, 2017.

DENZIN, N. K. The researchact: a theoreticalintroductiontosociologicalmethods. 2. ed. New York: McGraw-Hill, 1978.

DOLTO, F. La cause des enfants. Paris: Éditions Robert Laffont, 1985.

ERICKSON, F. Qualitative methods in research on teaching. In: WITTROCK, M. (ed.). Handbook of research on teaching. Chicago: Macmillan, 1986. p. 119-161.

FERREIRA, M. Os estranhos “sabores” da perplexidade numa etnografia com crianças em jardim de infância. In: CARIA, T. (org.). Experiência etnográfica em ciências sociais. Porto: Edições Afrontamento, 2002. p. 149-166.

“- Ela é a nossa prisioneira!” - Questões teóricas, epistemológicas e éticometodológicas a propósito dos processos de obtenção da permissão das crianças pequenas numa pesquisa etnográfica. Revista Reflexão e Ação, Santa Cruz do Sul, v.18, n.2, p.151182, 2010.2 Disponível em: <https://online.unisc.br/seer/index.php/reflex/article/viewFile/1524/1932>. Acesso em: 10 dez. 2018.

FOCHI, P. S. “Mas os bebês fazem o quê no berçário, hein?”: documentando ações de comunicação, autonomia e saber-fazer de crianças de 6 a 14 meses em contextos de vida coletiva. 2013. 171 f. Dissertação (Mestrado em Educação) - Faculdade de Educação, Universidade Federal do Rio Grande do Sul, Porto Alegre, 2013.

GEERTZ, C. Uma descrição densa: por uma teoria interpretativa da cultura. In: A Interpretação das Culturas. Rio de Janeiro: LTC,1989. p. 13-41.

GOBBATO, C. Os bebês estão por todos os espaços: dos bebês na sala do berçário aos bebês nos contextos de vida coletiva da escola infantil. 2011. 221 f. Dissertação (Mestrado em Educação) - Faculdade de Educação, Universidade Federal do Rio Grande do Sul, Porto Alegre, 2011.

GOTTLIEB, A. Para onde foram os bebês? Em busca de uma antropologia de bebês (e de seus cuidadores). Psicologia USP, São Paulo, v. 3, n. 20, p. 313-336, jul./set. 2009.

Tudo começa na outra vida: a cultura dos recém-nascidos na África. São Paulo: Fap-Unifesp, 2013.

GRAUE, E.; WALSH, D. Investigação etnográfica com crianças: teorias, métodos e ética. Lisboa: Fundação Calouste Gulbenkian, 2003.

GRAHAN, A.; FITZGERALD, R. O progresso da participação das crianças: explorando o potencial de uma atitude dialógica. Childhood, 17(3), 2010, p. 343-359.

LIEBEL, M. Infanciaslatinoamericanas: Civilización racista y limpieza social. Ensayo sobre violenciascoloniales y postcoloniales. Sociedad e Infancias, Madrid,v. 1, 2017, p. 1938.

MAYALL, B. Une Histoire de laSociologie de l'Enfance de l'Angleterre. SéminaireSociologie de l'Enfancedirigé par RégineSirota, Paris: 30 avril 2009.

MARCHI, R. de C. Pesquisa Etnográfica com Crianças: participação, voz e ética. Educação \& Realidade, Porto Alegre, v. 43, n. 2, p. 727-746, abr./jun. 2018. Disponível em: <http://dx.doi.org/10.1590/2175-623668737>. Acesso em: 18 out. 2018.

MOLLO-BOUVIER, S. Lesdimensionssociologiquesdesmodes de viedes enfants. In: SAADI-MOKRANI, D (ed.). Sociétés et culturesenfantines - Actesdu coloque. Université Charles de Gaulle Lille, nov., 1997.

MONTANDON, C. De l'étude de lasocialisationdes enfants à laSociologie de l'enfance. Nécessité ou ilusionépistémologique? In: SIROTA, R. (dir.). Élementspour une Sociologie de L'enfance. Rennes: PressesUniversitaires de Rennes, 2006. p. 41-49. 
NEYRAND, G. L'enfant, la mère et la question du pére: un bilan critique de l'évolution des saviors sur la petite enfance. Paris: PressesUniversitaires de France, 2000.

PEREIRA, R. F. As crianças bem pequenas na produção de suas culturas. 2011. $206 \mathrm{f}$. Dissertação (Mestrado em Educação) - Faculdade de Educação, Universidade Federal do Rio Grande do Sul, Porto Alegre, 2011.

. Os processos de socializ(ação) entre os bebês e os bebês e adultos no contexto da Educação Infantil. 2015. 249 f. Tese (Doutorado em Educação) - Faculdade de Educação, Universidade Federal do Rio Grande do Sul, Porto Alegre, 2015.

PIORSKI, G. O brinquedo e a imaginação da terra: um estudo das brincadeiras do chão e suas interações com o elemento fogo. 2013. 137 f. Dissertação (Mestrado em Ciência das Religiões) - Programa de Pós-Graduação em Ciências das Religiões, Universidade Federal da Paraíba, João Pessoa, 2013.

PROUT, A. Reconsiderar a nova sociologia da infância. Braga: Universidade do Minho; Instituto de Estudos da Criança, 2004. (texto digitado).

RAYOU, P. La grande école:Approchesociologiquedescompétencesenfantines. Paris:PressesUniversitaires de France, 1999.

ROSEMBERG, F. Educação para quem? Ciência e Cultura, São Paulo, v. 28, n.12, p. 1.466-1.471, 1976.

ROGOFF, B. A natureza cultural do desenvolvimento humano. Porto Alegre: Artmed, 2005.

SARMENTO, M. J. O Estudo de caso etnográfico em educação. In: ZAGO, N. et al. Itinerários de pesquisa: perspectivas qualitativas em sociologia da educação. Rio de Janeiro: DP\&A, 2003. p.137-179.

As culturas da infância nas encruzilhadas da segunda modernidade. In: SARMENTO, M. J; CERISARA, A. B. (org.). Crianças e miúdos: perspectivas sociopedagógicas da infância e educação. Porto:Asa Editores, 2004. p. 9-34.

. Sociologia da infância:correntes e confluências. In: Relatório de exames e provas de agregação. Sociologia dainfância. Braga: IEC/UMinho, 2007.

SCHMITT, R. V. “Mas eu não falo a língua deles!”: as relações sociais de bebês num contexto de Educação Infantil. 2008. 217 f. Dissertação (Mestrado em Educação) - Centro de Ciências da Educação, Universidade Federal de Santa Catarina, Florianópolis, 2008.

SIMON, C.; DELALANDE, J. Enfants scénaristes, enfants acteurssociaux: rencontre de deuxregardssurlacour de récréation. RevueLesSciences de l'éducation: Pourl'ère nouvelle, Territoiredes enfants, Caen, v. 39, n. 2, p. 89-102, 2006.

SOARES, N. F. A Investigação Participativa no Grupo Social da Infância. Braga: IEC/Uminho, 2003. Texto Digitado.

A investigação participativa no grupo social da infância. Currículo Sem Fronteiras, 6(1), 2006, p. 25-40.

TOMÁS, C.; SOARES, N. F. Infância, Protagonismo e Cidadania: contributos para uma análise sociológica da cidadania da infância. Revista Fórum Sociológico, Lisboa, 11(12), p. 349-361, 2004. 